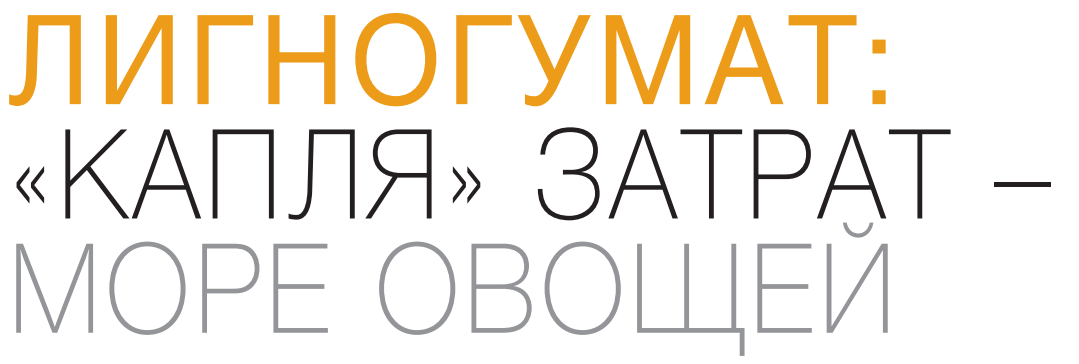

\title{
LIGNOHUMATE: LITTLE EXPENSES, MANY VEGETABLES
}

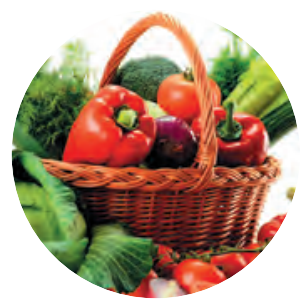

Кохан C.K.

Kokhan S.K.

ООО «ЛИГНОГУМАТ " Санкт-Петербург 8 (812) 600-46-01 Москва 8 (495) 789-65-17

\begin{abstract}
Важное место в системе «растение - вода - удобрение» занимают гуминовые вещества. Применение их в технологиях выращивания овощных культур с использованием капельного полива позволяет повысить коэффициент усвоения питательных веществ из внесенных удобрений и почвы. В данной статье хотелось бы подробнее осветить такой препарат, как Лигногумат - комплексный препарат, гуминовое удобрение, обладающее свойствами антистрессанта, иммуномодулятора, прилипателя. Испытания показали, что применение Лигногумата через систему капельного полива в комплексе с некорневыми обработками дает достоверную прибавку урожайности (5-20\% в зависимости от фона и технологии) на овощных культурах при различных технологиях выращивания. Также наблюдается устойчивое ускорение (от 3 до 12 суток) в развитии растений с увеличением доли выхода ранней продукции. Лигногумат можно использовать как для обработки семян, так и для внекорневых подкормок.
\end{abstract}

\section{Ключевые слова: гуминовые удобрения, лигногумат, капельный полив, овощные культуры.}

\author{
LLC 'LIGNOGUMAT' \\ Russia, Saint-Petersburg, tel. 8 (812) 600-46-01 \\ Russia, Moscow, tel. 8 (495) 789-65-17
}

\begin{abstract}
Humic compounds occupy the important place in the chain plant - water. Their application in technologies for vegetable plant growing with the use of drip irrigation enables to increase the coefficient of nutrient compound assimilation from soil with applied fertilizers. The preparation 'Lighohumate' presented in the article is integrated fertilizer, possessing the properties of anti-stress, immunomodulator and sticking agent. This preparation has the highest content of humic acids to $20 \%$ for liquid and to $90 \%$ for dried, consequently it has a powerful influence on plant organism, opening hidden biological reserves, and improving the crop productivity. The experimental tests showed that 'Lighohumate' application trough drip irrigation system together with foliage fertilizers had given significant yield augmentation; $5-20 \%$ depending on medium and technology in vegetable crops cultivated with different agricultural techniques. The permanent speeding-up from 3 to 12 days was noticed in the course of plant development with increase of early yield outcome. 'Lighohumate' can be used as seed treatment agent as well as foliage fertilizer and already applied giving a result in many vegetable production enterprises.
\end{abstract}

Keywords: humic fertilizers, Lighohumate, drip irrigation, vegetable crops. вощи - продукты питания для чело-

века, без которых его рацион не может считаться полноценным. По медицинским нормам человеку необходимо потреблять до 119 кг овощей в год, но ни для кого не секрет, что россияне далеки от этих норм (92 кг). Однако хотелось бы отметить, что и производство овощей в России на данный момент не может полностью обеспечить эту потребность даже при учете возникновения платежеспособного спроса (обеспеченность по томату $60 \%$, по огурцу - 87\%, по луку - 85\%). Таким образом, для увеличения потребления овощей необходимо увеличение производства овощной продукции. Достичь этого возможно двумя путями, ростом площадей, занимаемых овощными культурами, либо ростом урожайности овощных культур на тех же площадях. Оба пути приемлемы для нас, однако сегодня хотелось бы остановиться на втором пути, а именно интенсификации производства. Так за счет чего же возможно увеличить выход продукции?

1. Высокопродуктивные сорта и гибриды; 2. Применение эффективных средств защиты растений;
3. Капельный полив и усиленное питание растений;

4. Использование физиологически активных веществ.

Это не все пути, но одни из основных. Сегодня хотелось бы остановиться на последних двух пунктах, а именно, на применении физиологически активных веществ и регулировании водного и питательного режимов.

Не секрет, что наиболее интенсивно овощеводство развивается в Южном Федеральном Округе и одним из важных факторов обеспечения высоких урожаев в данном регионе является наличие полива, так как при недостатке воды невозможно полноценное усвоение элементов питания. А без питания, соответственно, невозможно добиться высокой урожайности и рентабельности производства.

Важное место в системе «растение вода - удобрение» занимают гуминовые вещества. Применение их в технологиях выращивания овощных культур с использованием капельного полива позволяет повысить коэффициент усвоения питательных веществ из внесенных удобрений и почвы. Гуминовые вещества стимули- руют рост и развитие растений, а при внесении их через «каплю» повышают всасывающую способность корневых волосков; при внесении по листу в составе баковых смесей с пестицидами интенсифицируют процессы фотосинтеза и накопления запасающих веществ, снимают стрессы с растений от применения пестицидов.

На сегодняшний день существует великое множество всевозможных гуминовых препаратов. В данной статье хотелось бы подробнее осветить такой препарат, как Лигногумат.

Лигногумат - комплексный препарат, гуминовое удобрение, обладающее свойствами антистрессанта, иммуномодулято$\mathrm{pa}$, прилипателя. Обладая одним из самых высоких уровней содержания гуминовых кислот (от 20\% для жидких модификаций до 90\% для сухих) препарат мощно воздействует на растительный организм, открывая скрытые резервы организма, и способствует увеличению продуктивности культуры. Лигногумат можно использовать как для обработки семян, так и для внекорневых подкормок (особенно эффективно внесение в составе сложных баковых смесей), что довольно давно и результативно делают 
многие овощеводческие хозяйства. Благодаря полной растворимости (безбалластность) препарат активно применяется в системах капельного полива, как в открытом грунте, так и в защищенном.

В 2009-2010 годах нами были проведены очередные широкомасштабные производственные испытания по внесению Лигногумата через «каплю» на ряде овощных культур в условиях Юга России, Украины и Казахстана. Были получены положительные результаты.

Так, при внесении Лигногумата через систему капельного полива помимо увеличения урожайности (5-20\% в зависимости от фона и технологии), было отмечено ускорение роста и развития растений, усиление иммунитета.

На томате было отмечено более мощное развитие растений, ускорение вступления в плодоношение на 5-7 дней (получение более рентабельной продукции); равномерное окрашивание и дружное созревание; повышение устойчивости к альтернариозу.

На огурце - ускорение на 3-5 дней. Также ярко проявился антистрессовый эффект от применяемых пестицидов.

На перце - ускорение на 10-12 дней, повышение устойчивости растений $\mathrm{k}$ вирусу бронзовой пятнистости, более мощное развитие корневой системы. Также оказался интересен и тот факт, что рассада в опытном варианте была менее развита при высадке, а спустя 1-1,5 месяца «догнала» и «перегнала» контрольную группу в развитии.
Влияние Лигногумата на урожайность культур, выращенных на капельном поливе, т/га, Ростовская область, 2009 год. 1 - Перец сладкий, 2 - Огурец (Эколь F1).

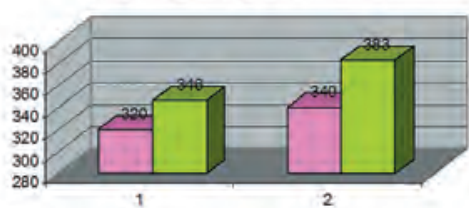

Впияние Лигногумата на урожайность культур, выращенных на капельном поливе,
« т/га, 2010 год. Казахстан. 1 - Морковь (Каскад) F1), 2-Картофель (сорт Невский), 3 - Лук репчатый (сорт Халцедон).

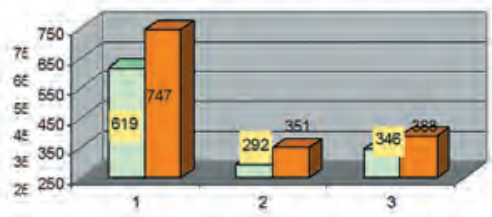

На луке репчатом наблюдался ежесуточный прирост выше контрольного на 2 см, а в развитии наблюдалось опережение на 1-2 листа. Растения выглядели более мощными, окраска листа - темнозеленая.

На картофеле, моркови, капусте белокочанной - более мощное развитие растений, темно-зеленая окраска листьев. Большая устойчивость к болезням.

Таким образом, хотелось бы отметить, что применение Лигногумата через систему капельного полива в комплексе с некорневыми обработками дает достоверную прибавку урожайности (5-20\% в зависимости от фона и технологии) на овощных культурах при различных технологиях
Влияние Лигногумата на урожайность культур, выращенных на капельном поливе, т/ra, Волгоградская область, 2009 год. 1 Томат (Сопероссо F1), 2 - Огурец (Пасалимо F1), 3 - Лук репчатый (сорт Халцедон).

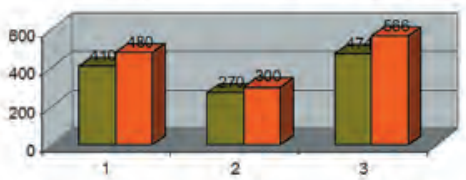

Влияние Липногумата на урожайность культур, ыращенных на капельном поливе, т/га, Украина, 2010 год. 1 - Лук репчатый (сорт Сквирский), 2. Капуста белокочанная (Arpeccop F1)

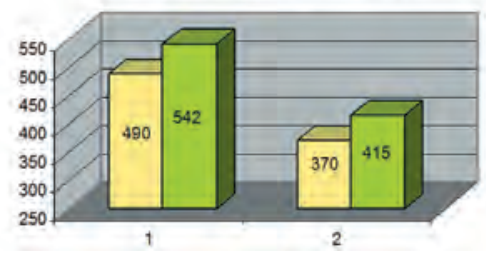

выращивания. Также наблюдается устойчивое ускорение (от 3 до 12 дней) в развитии растений с увеличением доли выхода ранней продукции. Особое внимание в процессе выращивания культур необходимо уделить питательному режиму.

Об экономике: соотношение дополнительно полученной прибыли к дополнительным затратам на внесение Лигногумата составляет 1:15-35, то есть 1 рубль затрат на Лигногумат приносит от 15 до 35 рублей прибыли.

Применение гуминового препарата «Лигногумат» в системах капельного полива при выращивании картофеля и овощей очень перспективно, как в биологическом плане, так и особенно в экономическом.

\section{lignohumate.ru О०० «Аигногумат»}

\section{r. Санкт-Петербург}

Малоохтинский пр., 61А

+7 (812) 600-46-01

\section{r. Москва \\ r. Красногорск}

+7 (495) 789-65-16
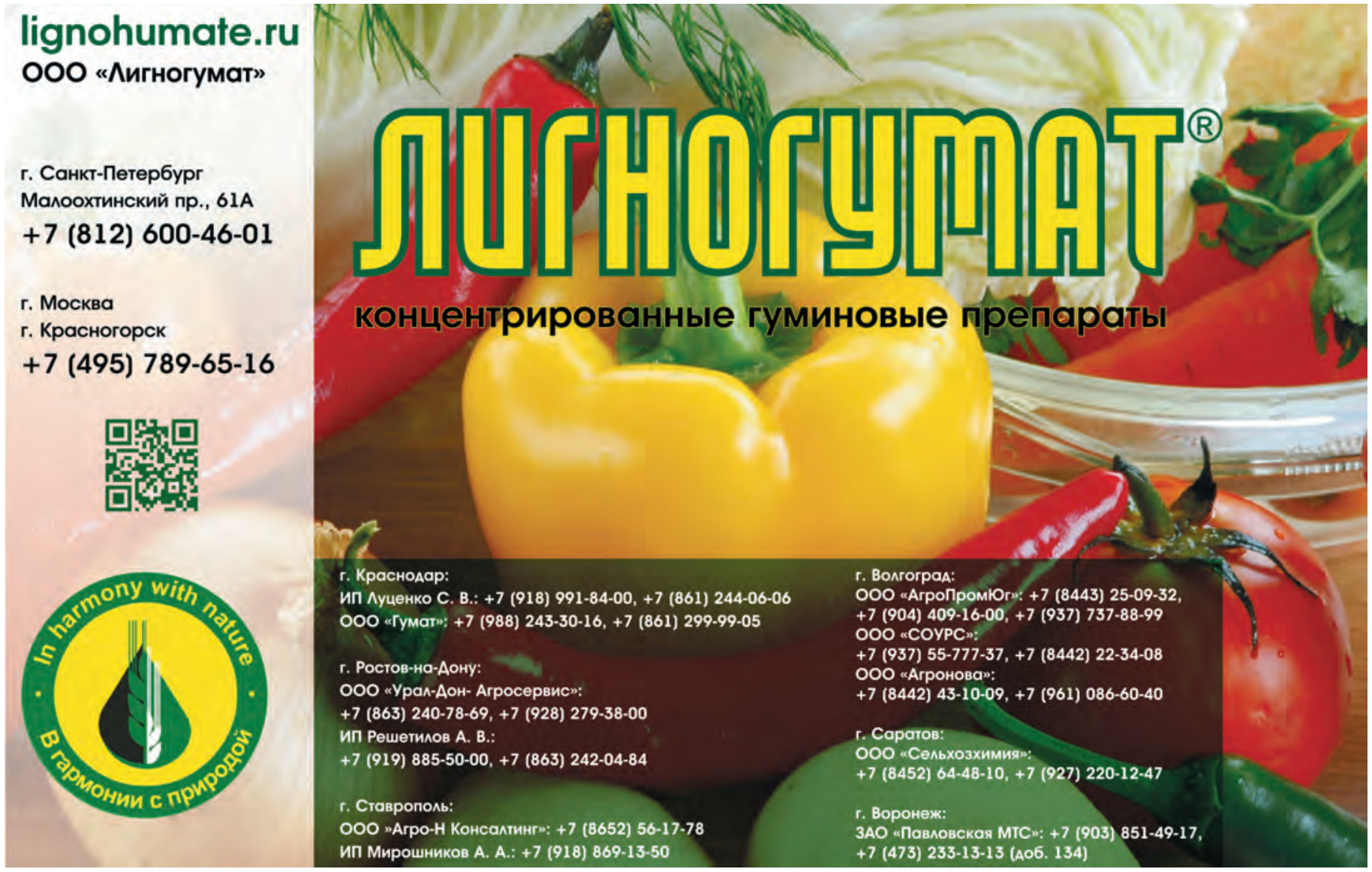